\title{
Risk of radiation pneumonitis in patients with emphysema after stereotactic body radiotherapy for non-small cell lung cancer assessed by quantitative CT
}

\author{
FUMIYA UCHIYAMA ${ }^{1}$, HIDETSUGU NAKAYAMA ${ }^{2}$, YUICHIRO TAKEDA ${ }^{3}$, \\ WENJIE WANG $^{4}$, RYOGO MINAMIMOTO ${ }^{5}$ and TSUYOSI TAJIMA ${ }^{1}$
}

\begin{abstract}
Departments of ${ }^{1}$ Radiology, ${ }^{2}$ Radiation Oncology and ${ }^{3}$ Respiratory Medicine, National Cancer Center for
Global Health and Medicine, Tokyo 162-8655, Japan; ${ }^{4}$ Department of Radiation Oncology,

The Affiliated Suzhou Hospital of Nanjing Medical University, Suzhou, Jiangsu 0086-215000, P.R. China;

${ }^{5}$ Department of Nuclear Medicine, National Center for Global Health and Medicine, Tokyo 162-8655, Japan
\end{abstract}

Received November 28, 2019; Accepted May 25, 2020

DOI:10.3892/mco.2020.2073

\begin{abstract}
Quantitative CT assessment of patients with pulmonary emphysema is used to measure pulmonary function. The present study evaluated whether the quantitative $\mathrm{CT}$ value can accurately estimate the risk of radiation pneumonitis (RP) after stereotactic body radiotherapy (SBRT) for non-small cell lung cancer (NSCLC) in patients with and without emphysema. A total of 80 patients with stage I NSCLC receiving SBRT at a dose of 50 or 60 Gy in five fractions at our hospital between November 2003 and October 2015 were included in the analysis. A total of $33(41 \%)$ patients were diagnosed with emphysema on CT examination. Dosimetric parameters, quantitative CT percentage value of low attenuation area (LAA\%) in the whole lung, and average whole lung CT density values were used to examine the risk of RP. Among the 80 patients, $26(33 \%)$ and $3(4 \%)$ experienced Grade 1 and Grade 2 RP, respectively, during the median observation period of 18.8 (1.8-106.8) months. The RP rate for patients with a LAA\% (<-910 HU) of $\leq 25 \%$ was significantly higher than that of subjects with LAA\% (<-910 HU) >25\% (P=0.037). The RP rate in subjects with an average $\mathrm{HU}$ value of $>-790 \mathrm{HU}$ was significantly higher compared with that of patients with $\leq-790 \mathrm{HU}(\mathrm{P}=0.036)$. Age (hazard ratio $[\mathrm{HR}]=2.46 ; \mathrm{P}=0.03)$ and average $\mathrm{HU}(\mathrm{HR}=3.39 ; \mathrm{P}=0.02)$ were significantly associated with RP, whereas mean lung dose was not identified to be significant in multivariate analysis. The quantitative $C T$ value was associated with RP after SBRT.
\end{abstract}

Correspondence to: Dr Hidetsugu Nakayama, Department of Radiation Oncology, National Cancer Center for Global Health and Medicine, 1-21-1 Toyama Shinjuku, Tokyo 162-8655, Japan

E-mail: hnakayama@hosp.ncgm.go.jp

Key words: stereotactic body radiotherapy, lung cancer, emphysema, radiation pneumonitis, quantitative CT value, non-small cell lung cancer

\section{Introduction}

Chronic obstructive pulmonary disease (COPD) is a risk factor for lung cancer (1). Patients with non-small cell lung cancer (NSCLC) with coexisting COPD tend to have poor survival $(2,3)$. They also are at high risk of mortality after surgical resection (4). Compared with surgery, stereotactic body radiotherapy (SBRT) has a lower mortality risk and results in higher survival in patients with severe COPD (5). SBRT is now the treatment of choice for non-operable early-stage NSCLC; however, radiation pneumonitis (RP) may occur as an adverse event (6).

Dosimetric parameters, including mean lung dose and percentage of lung volume irradiated with $\geq 20 \mathrm{~Gy}$, can estimate the risk of RP (7-9). However, whether patients with pulmonary emphysema are at a higher risk for RP is unclear.

Quantitative CT assessment of patients with emphysema is now used to measure pulmonary function (10-14) since Hayhurst et al (15) reported a correlation between emphysema and lung CT values in low attenuation areas. By quantitative assessment, we previously showed that patients with low average Hounsfield units (HU) of the whole lung had a low rate of RP after conventional low dose radiotherapy (75 Gy administered in 30 fractions) (16). However, the major criticism of our report was the use of a conventional low dose of SBRT rather than a high dose.

In this study, to investigate whether quantitative CT measurement and/or lung irradiated dose were associated with $\mathrm{RP}$, we used a high dose of SBRT and observed the rates of RP in patients with and without emphysema.

\section{Patients and methods}

Patients. This retrospective study was approved by the institutional review board of the National Center for Global Health and Medicine Ethics Committee. Informed consent was waived by the Ethics Committee due to the retrospective nature of the study. According to the approval, informed consent from the patients was not required. Inclusion criteria were 
histologically/cytologically confirmed NSCLC or the tumor size enlarged more than $25 \%$ on sequential CT examination, clinical stage I (T1/2N0M0) staged by CT examination, age $\geq 20$ years, Eastern Cooperative Oncology Group performance status 0-2 and no history of radiation therapy. Exclusion criteria were interstitial pneumonitis or huge bullae on CT examination, centrally located tumor, history of chemotherapy, sever psychologically disease and active infectious disease. Between November 2003 and October 2015, patients with stage I NSCLC receiving SBRT at a dose of 50 or 60 Gy over five fractions at our hospital were studied. Eighty consecutive patients were identified. The median age was 75.5 years (range, 29-95 years), 54 and 26 patients were male and female, respectively, and there were 49 and $31 \mathrm{~T} 1$ and T2 tumors, respectively (Table I). There were no patients with interstitial pneumonitis. Patients with interstitial pneumonitis did not undergo SBRT because of a risk of pneumonitis in our treatment policy. Centrally located tumor was treated by a different dose fraction. None underwent chemotherapy or molecular targeting therapy during the observation period. Two experienced radiologists diagnosed 33 patients with emphysema based on CT examination before radiotherapy. $\mathrm{RP}$ was determined according to common terminology criteria for adverse events (CTCAE v. 4.0). All patients underwent physical examination, blood tests, and chest X-rays at least every 4 months up to 3 years, and then every 6 months. CT examinations were performed at least every 6 months up to 3 years and then every year or if tumor enlargement was suspected upon chest X-ray.

Radiotherapy technique and dose evaluation. A planning CT was acquired with patients in the supine position on a vacuum cushion with their arms raised. To assess intra-fraction tumor movement, four-dimensional (4-D) CT images were obtained using commercial software (Real-Time Position Management System [RPM] system $^{\circledR}$, Varian Medical System, Inc.). The respiratory cycle was controlled by a self-monitoring device for respiratory movement (Abches ${ }^{\circledR}$, APEX Medical, Inc.) Ten equally spaced respiratory time bins from CT images were reconstructed from 4-D CT. An inspiratory phase CT image was also obtained using a self-monitoring device. Typically, three bins were used to create the gross tumor volume (GTV) in each bin. Internal target volume (ITV) was created from each GTV and contoured on an inspiratory phase CT image. Planning target volume (PTV) was generated by adding $5 \mathrm{~mm}$ to the ITV. Respiratory-gated irradiation or breath-hold technique was used according to patients' respiratory cycles and tumor movement. CT images were obtained within at least 10 days before the initiation of radiotherapy. Dose calculation was performed by a planning system (Eclipse ver. $10^{\circledR}$, Varian Medical Systems). A dose of 50 or 60 Gy given in five fractions was prescribed to the isocenter. Five to 10 (median, seven) ports to optimize the directions for non-coplanar static beams or dynamic arcs using $6 \mathrm{MV}$ energy were planned. Mean lung dose and the percentage of normal lung volume receiving $\geq 20$ Gy (V20) and >5 Gy (V5) were evaluated in the inspiratory phase of CT images. On-board cone beam CT was performed to reduce inter-fraction error before every irradiation session.

CT assessment of emphysema. Parameters of the 64-detector CT (Aquilion TSX-101HA, Toshiba Medical System, Inc.)
Table I. Patient characteristics.

\begin{tabular}{lc}
\hline Variable & Value $(\mathrm{n}=80)$ \\
\hline Median age, years (range) & $75.5(29-95)$ \\
Sex, $\mathrm{n}(\%)$ & \\
Male & $54(67.5)$ \\
Female & $26(32.5)$ \\
T factor & \\
T1 & $49(61.3)$ \\
T2 & $31(38.8)$ \\
Tumor location in lung, $\mathrm{n}(\%)$ & \\
Right lung & $49(61.3)$ \\
Left lung & $31(38.8)$ \\
Tumor location in lobe, $\mathrm{n}(\%)$ & \\
Upper lobe & $31(38.8)$ \\
Middle or lingual lobe & $11(13.8)$ \\
Lower lobe & $38(47.5)$ \\
Histological type, $\mathrm{n}(\%)$ & \\
Adenocarcinoma & $43(53.8)$ \\
Squamous cell carcinoma & $16(20)$ \\
NSCLC & $4(5)$ \\
LCNEC & $1(1)$ \\
Unproven & $16(20)$ \\
\hline
\end{tabular}

NSCLC, non-small cell lung cancer; LCNEC, large cell neuroendocrine cancer.

were as follows: Auto exposure control mA (tube current range, 40-200 $\mathrm{mA}$ ); tube voltage, $120 \mathrm{KV}$; and gantry rotation time, $0.5 \mathrm{sec}$. CT data were reconstructed in an axial CT image with $1.6-\mathrm{mm}$ section thickness. CT values varied with the CT scanner, and thus all patients underwent CT using the same machine. The details of quantitative assessment by CT have been reported elsewhere (16). CT images of the inspiratory phase were obtained from a planning CT, and quantitative assessment of the percentage of lung CT voxels below the threshold of -910 HU were analyzed (Synapse Vincent ${ }^{\circledR}$ software, Fujifilm Co.). The percentage of low attenuation areas (LAA\%) in both whole lungs and the average density value of both lungs were obtained.

Statistical analysis. Quantitative CT value and dosimetric parameters were analyzed by Wilcoxon's rank-sum test. The time to RP development was calculated from the first day of SBRT. The time to RP was estimated by Kaplan-Meier analysis and compared with log-rank tests. Cox's proportional hazard model was used to analyze risk factors for RP. The CT values assessed for emphysema were evaluated by a receiver operating characteristic (ROC) curve. Most cases of radiation pneumonitis occurred within 1 year, and hence ROC analysis is an acceptable approach to clarify radiation pneumonitis. A two-sided probability value $(\mathrm{P}<0.05)$ was considered statistically significant. Statistical analysis was performed with commercial software (STATA v. $13^{\circledR}$, StataCorp). 
Table II. Quantitative CT value for non-emphysema and emphysema.

\begin{tabular}{lcrr}
\hline Quantitative CT value & $\begin{array}{c}\text { Total } \\
(\mathrm{n}=80)\end{array}$ & $\begin{array}{r}\text { Non-emphysema } \\
(\mathrm{n}=47)\end{array}$ & $\begin{array}{r}\text { Emphysema } \\
(\mathrm{n}=33)\end{array}$ \\
\hline $\begin{array}{l}\text { Percentage of low attenuation area less than }-910 \mathrm{HU}, \% \\
\text { Average HU of whole lung, HU }\end{array}$ & $\begin{array}{c}29.5 \pm 2.1 \\
-772.4 \pm 59.3\end{array}$ & $\begin{array}{r}6.7 \pm 1.3 \\
-737.2 \pm 6.4\end{array}$ & $\begin{array}{r}36.2 \pm 2.8 \\
-822.5 \pm 6.7\end{array}$ \\
\hline
\end{tabular}

Data are presented as the mean $\pm \mathrm{SD}$. HU, Hounsfield unit.

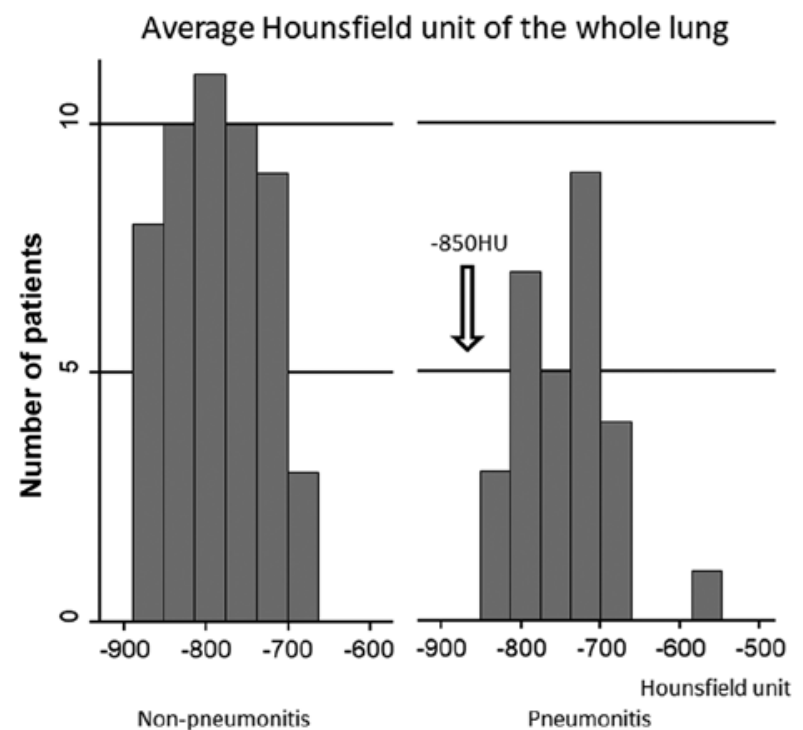

Percent of low attenuation area less than $-910 \mathrm{HU}$

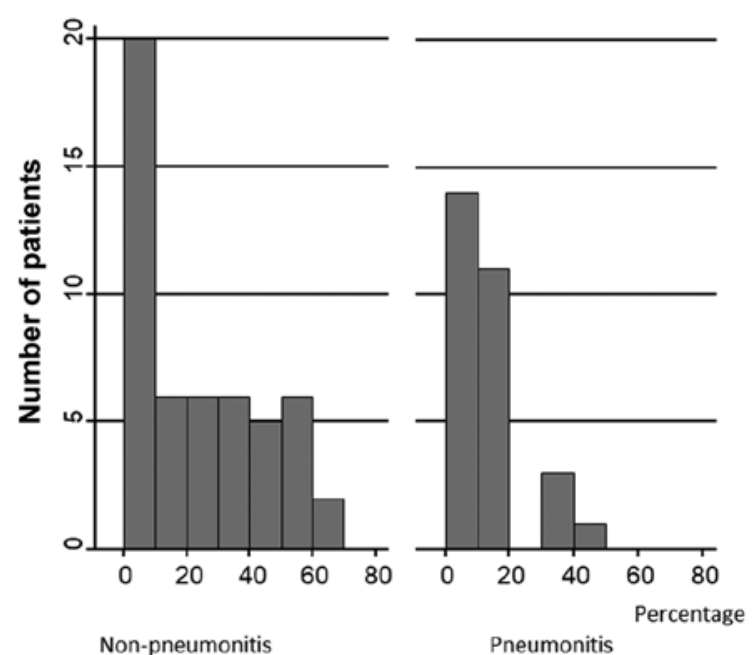

Figure 1. Histogram showing the number of patients with an average density (HU) in both lungs and a LAA\% of -910 HU or less. Radiation pneumonitis did not occur in patients with an average density $<-850 \mathrm{HU}$ (arrow). HU, Hounsfield unit; LAA\%, percentage of low attenuation area.

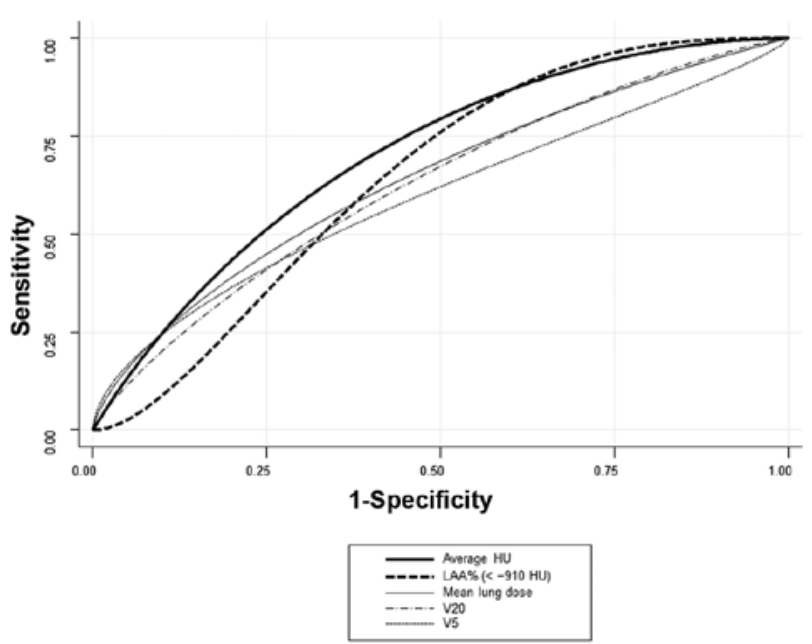

Figure 2. Receiver operating characteristic curve analysis of radiation pneumonitis. The area under the curve values of average HU, mean lung dose, LAA\% of -910 HU, V20 and V5 were 0.692, 0.643, 0.641, 0.619 and 0.591 , respectively. HU, Hounsfield unit; LAA\%, percentage of low attenuation area.

\section{Results}

$R P$ rate. During the median observation period of 18.8 (1.8-106.8) months, $26(33 \%)$ and three (4\%) patients experienced Grade 1 and Grade 2 RP, respectively. Three patients with Grade 2 RP were successfully treated with steroids. No patients suffered from $\geq$ Grade 3 RP. The median time to development of RP was 14 months. Actuarial RP rates at 6, 12 and 18 months were 16.9\% [95\% confidence interval (CI), 9.7-28.5\%)], $49.0 \%$ (95\% CI, 35.1-65.0\%), and 74.1\% (95\% CI, 51.6-92.0\%), respectively.

The quantitative CT value of emphysema. LAA\% (<-910 HU) in patients with emphysema was significantly higher than that in patients with non-emphysema $(\mathrm{P}<0.001$, Table II). The average $\mathrm{HU}$ of the whole lung in patients with emphysema was significantly lower than that in patients without emphysema $(\mathrm{P}<0.001)$. Fig. 1 shows the number of patients with an average $\mathrm{HU}$ of the whole lung and LAA\% of $-910 \mathrm{HU}$ and less. No patients who had an average $\mathrm{HU}$ of $\leq-850 \mathrm{HU}$ experienced RP (Fig. 1).

In ROC analysis of patients with and without emphysema, the AUC of LAA\% (<-910 HU) and average HU were 0.948 and 0.942 , respectively. Fig. 2 shows a ROC curve comparing patients with and without RP. The AUC of average HU, mean lung dose, LAA\% (<-910 HU), V20, and V5 were 0.692, 0.643 , $0.641,0.619$, and 0.591 , respectively.

$R P$ and the quantitative $C T$ value. Table III shows the difference in the quantitative $\mathrm{CT}$ value and dosimetric parameters between RP and non-RP. A LAA\% (<-910 HU) in patients 
Table III. Quantitative CT value and dosimetric parameters for non-pneumonitis and pneumonitis.

\begin{tabular}{|c|c|c|c|}
\hline Quantitative CT value and dosimetric parameters & Non-pneumonitis $(\mathrm{n}=51)$ & Pneumonitis $(\mathrm{n}=29)$ & P-value \\
\hline Percent of low attenuation area <-910 HU, \% & $22.9 \pm 2.1$ & $11.8 \pm 1.2$ & 0.037 \\
\hline Average HU of whole lung, HU & $-787.5 \pm 7.9$ & $-745.8 \pm 10.2$ & 0.004 \\
\hline $\mathrm{V} 20, \%$ & $5.4 \pm 0.4$ & $7.0 \pm 0.7$ & 0.078 \\
\hline $\mathrm{V} 5, \%$ & $17.8 \pm 0.8$ & $20.4 \pm 1.4$ & 0.178 \\
\hline Mean lung dose, Gy & $3.8 \pm 0.2$ & $4.6 \pm 0.3$ & 0.034 \\
\hline
\end{tabular}

V20 and V5 denotes the percentage of the whole lung volume irradiated with a dose of $\geq 20$ and $\geq 5$ Gy, respectively. HU, Hounsfield unit.

Table IV. Risk factors for radiation pneumonitis analyzed using a Cox proportional hazard model.

\begin{tabular}{lccc}
\hline Factor & Hazard ratio & 95\% CI & P-value \\
\hline Age (<75 years vs. $>75$ years) & 2.46 & $1.07-5.67$ & 0.03 \\
Sex (male vs. female) & 0.43 & $0.17-1.07$ & 0.07 \\
T factor (T1 vs. T2) & 2.04 & $0.90-4.62$ & 0.09 \\
Mean lung dose (<4 Gy vs. $>4$ Gy) & 1.75 & $0.80-3.85$ & 0.16 \\
Average CT value (<-790 cs. $>-790$ HU) & 3.39 & $1.24-9.24$ & 0.02 \\
\hline
\end{tabular}

HU, Hounsfield unit; CI, confidence interval.
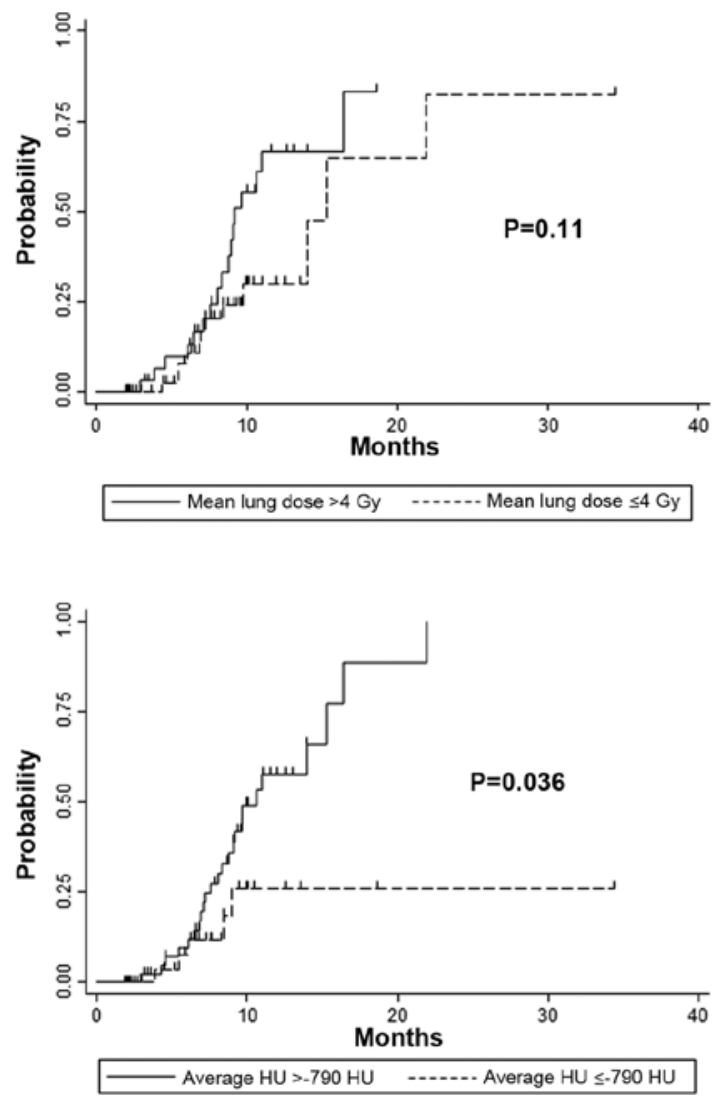
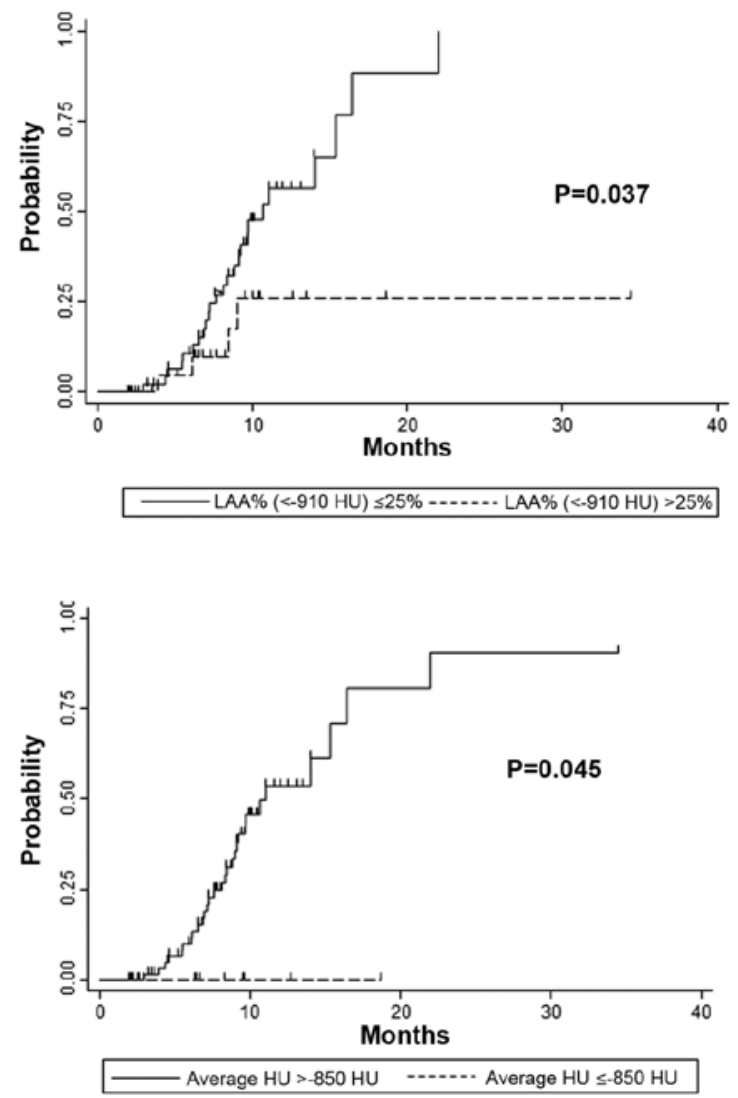

Figure 3. Kaplan-Meier analysis of patients with and without RP. The actuarial RP rate in patients with a mean lung dose of $\leq 4$ Gy was not significantly different from the rate in patients receiving $>4 \mathrm{~Gy}(\mathrm{P}=0.11)$. The RP rate in patients with a LAA $<-910 \mathrm{HU}$ of $\leq 25 \%$ was significantly higher compared with that of patients with a LAA\% <-910 HU of $>25 \%(\mathrm{P}=0.037)$. The RP rate in patients with average HU in the whole lung of $>-790 \mathrm{HU}$ was significantly higher compared with that in patients with an average $\mathrm{HU}$ in the whole lung of $\leq-790 \mathrm{HU}(\mathrm{P}=0.036)$. The RP rate in patients with an average $\mathrm{HU}$ of the whole lung of $>-850 \mathrm{HU}$ was significantly higher compared with that in patients with an average HU of the whole lung of $\leq-850 \mathrm{HU}(\mathrm{P}=0.045)$. No patient with an average $\mathrm{HU}$ of $\leq-850 \mathrm{HU}$ developed RP. HU, Hounsfield unit; LAA\%, percentage of low attenuation area; RP, radiation pneumonitis. 
without RP was significantly higher than that in patients with $\mathrm{RP}(\mathrm{P}=0.037)$. The average density of the whole lung in patients without RP was significantly lower than that in patients with RP $(\mathrm{P}=0.004)$. V20 $(\mathrm{P}=0.078)$ and V5 $(\mathrm{P}=0.178)$ were not significantly different between subjects with and without RP. The mean lung dose in patients with RP was higher than that in patients without $\mathrm{RP}(\mathrm{P}=0.034)$. Fig. 3 shows $\mathrm{RP}$ rates analyzed by the Kaplan-Meier method. The RP rate with a mean lung dose of $<4$ Gy was not significantly different compared with doses $\geq 4$ Gy $(\mathrm{P}=0.11)$. The RP rate in LAA\% (<-910 HU) of $\leq 25 \%$ was significantly higher compared with that of subjects with an LAA\% (<-910 HU) >25\% (P=0.037). The RP rate in subjects with an average $\mathrm{HU}>-790 \mathrm{HU}$ was significantly higher compared with those with $\leq-790 \mathrm{HU}(\mathrm{P}=0.036)$. The $\mathrm{RP}$ rate at an average $\mathrm{HU}$ of $>-850 \mathrm{HU}$ was significantly higher compared with those with an average $\mathrm{HU}$ of $\leq-850 \mathrm{HU}$ $(\mathrm{P}=0.045)$.

Table IV shows age [hazard ratio $(\mathrm{HR})=2.46, \mathrm{P}=0.03$ ] and average $\mathrm{HU}(\mathrm{HR}=3.39, \mathrm{P}=0.02)$ were significant risk factors for RP by multivariate analysis. Sex, $\mathrm{T}$ factor, and mean lung dose were not significant.

\section{Discussion}

Radiation oncologists are concerned about RP after SBRT, especially in the case of emphysema. This study showed that patients with emphysema can be safely treated with SBRT. In our cohort, no patient suffered $\geq$ Grade $3 \mathrm{RP}$ and none had emphysema. Takeda et al (17) reported that patients with severe COPD could be treated with SBRT; however, they did not specifically distinguish between emphysema and COPD. Some authors also reported that patients with stage I NSCLC who had emphysema had a low rate of RP after SBRT $(18,19)$. Based on these results, we believe that emphysema is not a contraindication for SBRT.

In our previous study, the actuarial rates of RP at 6 and 12 months were 52 and $75 \%$, respectively, when a conventional dose of 75 Gy was administered in 30 fractions (16). In this study, the rate of RP at 12 and 18 months was 49 and 74\%, respectively. The rate of RP was similar in both studies, but RP events in SBRT were late compared with the conventional dose. Recently, a prospective randomized trial of an SBRT dose of $66 \mathrm{~Gy}$ given in three fractions compared with a conventional dose of 70 Gy given in 35 fractions (20) showed that the rate of RP was not significantly different between the two dose schedules, suggesting that RP may not be prevented by hyperfractionation.

The effectiveness of the quantitative CT method relating LAA\% and anatomical emphysema has been proven. Gevenois et al $(21,22)$ described a cutoff value of $-950 \mathrm{HU}$ corresponding closely with pathological emphysema. They noted a cutoff value of >-950 HU overestimated emphysema whereas <-950 HU underestimated emphysema. Müller et al (23) reported a <-910 HU threshold of LAA was the best predictor for discrimination between normal lung and emphysema. Therefore, we chose $-910 \mathrm{HU}$ as the cut-off value for LAA. Reports on the correlation between pulmonary function tests and LAA\% have reported cut-off thresholds of LAA from -960 to $-860 \mathrm{HU}(10,11,13,14)$.

This study showed that quantitative $\mathrm{CT}$ is a good predictor for RP risk. Another study suggested that quantitative
CT values correlated with RP after radiotherapy (24). Yamamoto et al (24) showed a quantitative CT value of LAA\% was associated with Grade 1 RP, but not with Grade 2 and 3 because they were affected by other factors such as V20. These results were similar to ours, where no patient had Grade 3 or higher RP in our study, and thus we did not observe LAA\% or average HU to be associated with Grade 3 RP. The previous study showed that V20 was associated with radiation pneumonitis; however, we did not include interstitial disease in our study and used the average $\mathrm{HU}$ of the whole lung, which we believe to be the reason for the different results.

This study showed that the average HU of the whole lung was associated with RP, with a higher AUC for average HU compared with that of LAA\%. The patients with an average HU of <-850 HU (implying severe emphysema) did not develop RP. Patients with severe emphysema had a low risk of RP, which is in accordance with our previous studies $(16,25)$. We speculate that average whole lung $\mathrm{HU}$ is a convenient measurement in quantitative CT assessment to estimate the risk RP.

This study had some limitations. This research was a retrospective single institution study and included relatively small numbers. Smoking history and histological grade information were not available. However, in this study we showed that the average HU value of the whole lung was associated with RP after SBRT. A prospective multi-institution study is required to validate the association between the quantitative $\mathrm{CT}$ value and RP after SBRT.

In conclusion, pulmonary emphysema patients, especially those with severe emphysema, can safely undergo SBRT. The quantitative CT value was associated with RP after SBRT.

\section{Acknowledgements}

The authors would like to thank Dr Nikki March for editing a draft of this manuscript.

\section{Funding}

No funding was received.

\section{Availability of data and materials}

The datasets used and/or analyzed during the current study are available from the corresponding author on reasonable request.

\section{Authors' contributions}

The present study was designed by HN and RM. Data of CT values were analyzed by TT, YT and FU. Statistical analyses was performed by HN and WW. The manuscript was written by $\mathrm{HN}$ with contributions from FU, YU, WW and RM. All authors read and approved the final manuscript.

\section{Ethics approval and consent to participate}

The present retrospective study was approved by the Institutional Review Board of the National Center for Global Health and Medicine Ethics Committee (approval no. NCGM-G-002164-00). The requirement for informed 
consent was waived by the Ethics Committee due to the retrospective nature of the study.

\section{Patient consent for publication}

Not applicable.

\section{Competing interests}

The authors declare that they have no competing interests.

\section{References}

1. de-Torres JP, Wilson DO, Sanchez-Salcedo P, Weissfeld JL, Berto J, Campo A, Alcaide AB, García-Granero M, Celli BR and Zulueta JJ: Lung cancer in patients with chronic obstructive pulmonary disease. Development and validation of the COPD lung cancer screening score. Am J Respir Crit Care Med 191: 285-291, 2015.

2. Zhai R, Yu X, Shafer A, Wain JC and Christiani DC: The impact of coexisting COPD on survival of patients with early-stage non-small cell lung cancer undergoing surgical resection. Chest 145: 346-353, 2014.

3. Putila J and Guo NL: Combining COPD with clinical, pathological and demographic information refines prognosis and treatment response prediction of non-small cell lung cancer PLoS One 9: e100994, 2014.

4. Brunelli A, Kim AW, Berger KI and Addrizzo-Harris DJ: Physiologic evaluation of the patient with lung cancer being considered for resectional surgery: Diagnosis and management of lung cancer, 3rd ed: American College of Chest Physicians evidence-based clinical practice guidelines. Chest 143 (Suppl 5): e166S-e190S, 2013.

5. Palma D, Lagerwaard F, Rodrigues G, Haasbeek C and Senan S: Curative treatment of stage I non-small-cell lung cancer in patients with severe COPD: Stereotactic radiotherapy outcomes and systematic review. Int J Radiat Oncol Biol Phys 82: 1149-1156, 2012.

6. Chi A, Liao Z, Nguyen NP, Xu J, Stea B and Komaki R: Systemic review of the patterns of failure following stereotactic body radiation therapy in early-stage non-small-cell lung cancer: Clinical implications. Radiother Oncol 94: 1-11, 2010.

7. Baker R, Han G, Sarangkasiri S, DeMarco M, Turke C, Stevens CW and Dilling TJ: Clinical and dosimetric predictors of radiation pneumonitis in a large series of patients treated with stereotactic body radiation therapy to the lung. Int J Radiat Oncol Biol Phys 85: 190-195, 2013.

8. Barriger RB, Forquer JA, Brabham JG, Andolino DL, Shapiro RH, Henderson MA, Johnstone PA and Fakiris AJ: A dose-volume analysis of radiation pneumonitis in non-small cell lung cancer patients treated with stereotactic body radiation therapy. Int J Radiat Oncol Biol Phys 82: 457-462, 2012.

9. Zhao J, Yorke ED, Li L, Kavanagh BD, Li XA, Das S, Miften M, Rimner A, Campbell J, Xue J, et al: Simple factors associated with radiation-induced lung toxicity after stereotactic body radiation therapy of the thorax: A pooled analysis of 88 studies. Int J Radiat Oncol Biol Phys 95: 1357-1366, 2016.

10. Ando K, Sekiya M, Tobino K and Takahashi K: Relationship between quantitative CT metrics and pulmonary function in combined pulmonary fibrosis and emphysema. Lung 191: 585-591, 2013.

11. Madani A, Van Muylem A and Gevenois PA: Pulmonary emphysema: Effect of lung volume on objective quantification at thin-section CT. Radiology 257: 260-268, 2010.
12. Wang G, Wang L, Ma Z, Zhang C and Deng K: Quantitative emphysema assessment of pulmonary function impairment by computed tomography in chronic obstructive pulmonary disease. J Comput Assist Tomogr 39: 171-175, 2015.

13. Schroeder JD, McKenzie AS, Zach JA, Wilson CG, Curran-Everett D, Stinson DS, Newell JD Jr and Lynch DA: Relationships between airflow obstruction and quantitative CT measurements of emphysema, air trapping, and airways in subjects with and without chronic obstructive pulmonary disease. AJR Am J Roentgenol 201: W460-W470, 2013.

14. Washko GR, Hunninghake GM, Fernandez IE, Nishino M, Okajima Y, Yamashiro T, Ross JC, Estépar RS, Lynch DA, Brehm JM, et al: Lung volumes and emphysema in smokers with interstitial lung abnormalities. N Engl J Med 364: 897-906, 2011.

15. Hayhurst MD, MacNee W, Flenley DC, Wright D, McLean A, Lamb D, Wightman AJ and Best J: Diagnosis of pulmonary emphysema by computerised tomography. Lancet 2: 320-322, 1984.

16. Saito T, Nakayama H, Yamada T, Shiraishi S and Tokuuye K: Is severe emphysema, as defined by quantitative CT measurement, a negative risk factor of radiation fibrosis? Br J Radiol 91: 20170921, 2018.

17. Takeda A, Kunieda E, Ohashi T, Aoki Y, Oku Y, Enomoto T, Nomura K and Sugiura M: Severe COPD is correlated with mild radiation pneumonitis following stereotactic body radiotherapy. Chest 141: 858-866, 2012.

18. Trovo M, Linda A, El Naqa I, Javidan-Nejad C and Bradley J: Early and late lung radiographic injury following stereotactic body radiation therapy (SBRT). Lung Cancer 69: 77-85, 2010

19. Kimura T, Matsuura K, Murakami Y, Hashimoto Y, Kenjo M, Kaneyasu Y, Wadasaki K, Hirokawa Y, Ito K and Okawa M: $\mathrm{CT}$ appearance of radiation injury of the lung and clinical symptoms after stereotactic body radiation therapy (SBRT) for lung cancers: Are patients with pulmonary emphysema also candidates for SBRT for lung cancers? Int J Radiat Oncol Biol Phys 66: 483-491, 2006.

20. Nyman J, Hallqvist A, Lund JA, Brustugun OT, Bergman B, Bergström P, Friesland S, Lewensohn R, Holmberg E and Lax I: SPACE-A randomized study of SBRT vs. conventional fractionated radiotherapy in medically inoperable stage I NSCLC. Radiother Oncol 121: 1-8, 2016.

21. Gevenois PA, de Maertelaer V, De Vuyst P, Zanen J and Yernault JC: Comparison of computed density and macroscopic morphometry in pulmonary emphysema. Am J Respir Crit Care Med 152: 653-657, 1995.

22. Gevenois PA, Koob MC, Jacobovitz D, De Vuyst P, Yernault JC and Struyven J: Whole lung sections for computed tomographic-pathologic correlations. Modified Gough-Wentworth technique. Invest Radiol 28: 242-246, 1993

23. Müller NL, Staples CA, Miller RR and Abboud RT: 'Density mask'. An objective method to quantitate emphysema using computed tomography. Chest 94: 782-787, 1988.

24. Yamamoto T, Kadoya N, Sato Y, Matsushita H, Umezawa R, Kubozono M, Ishikawa Y, Kozumi M, Takahashi N, Morishita Y, et al: Prognostic value of radiation pneumonitis after stereotactic body radiotherapy: Effect of pulmonary emphysema quantitated using CT images. Clin Lung Cancer 19: e85-e90, 2018.

25. Ishijima, M, Nakayama, H, Itonaga, T, Tajima Y, Shiraishi S, Okubo M, Mikami R and Tokuuye K: Patients with severe emphysema have a low risk of radiation pneumonitis following stereotactic body radiotherapy. Br J Radiol 88: 20140596, 2015. 